form

Vol I4, No 3 (2O2I)

\title{
Designing and Learning by Technological Mediation
}

\author{
Adoption, Adaptation, Attainment
}

\begin{abstract}
In this article, an instrumental case study of a practical course in assistive technologies in cooperation between Norway and Brazil shows how patients, design students, and therapists participate in designing and learning. The study reveals how conception and reception of design play out through mediation processes between stakeholders and artifacts. The study was framed in light of Alain Findeli's writings to challenge and inform current developments in design studio educational practices. To explain the solving of complex, ill-structured problems through design, Findeli proposed systems theory as a holistic philosophical perspective of the design process and design education. By asking what design is and how to teach it, I reiterate Findeli's ideas on design and design education. This article emphasizes the ubiquitous effects of technology through relationalist ontology and postphenomenological perspectives.
\end{abstract}

Keywords:

design conception, design reception, relationalism, postphenomenology, socio-technological

configuration

\section{INTRODUCTION: MULTIPLE PERSPECTIVES ON DESIGN}

It is now almost 20 years since Findeli's (2001) article on design education and theory was published. In this article, he called for a new perspective on how design and designing can be understood in the twenty-first century and asked what the consequences for higher design education might be. In his attempt to systematize how design schools teach, he reviewed the historical development of design education in the West, as it emerged from Bauhaus. He went on to criticize determinism and instrumental reason as well as the central role of economic factors in design. He claimed that this is reflected in the way design topics are formulated in design curricula, but also in everyday language. Accordingly, user factors are merely concerned with ergonomics and cognitive psychology and places an overemphasis on material products. Aesthetics are concerned only with shapes and material 
qualities, while ethics are based on the culture of business contracts and agreements. Findeli (2001, p. 6) considered this model to be part of the historical development of the design discipline, which he believed was connected to the vision of material progress.

He proceeded to explain that design needs to turn toward understanding the complex interplay and relationships that exist among interrelating subsystems that happen in user, social, and technological environments, complexities with which the designer must establish familiarity. Further, Findeli proposed that this approach was necessary because of the very dematerialization of design (Findeli, 2001, p. 15). According to Findeli, the vanishing product and shifting to services will characterize the future of design in accordance with sustainability imperatives. Furthermore, he (p. 10) suggested that problem solving, as a concept that explains design activity, is characterized by the positivist paradigm, and that the design discipline should be seen as a situated change of existing systems through implementation of design competences. Scientific inquiry explained in this way is carried into, instead of applied to, the field of the design project and of practice. This is how Findeli described the change of perspectives departing from Simon's functionalism:

The most widely-accepted (and practiced) logical structure of the design process is, therefore, the following: $1 \mathrm{~A}$ need or problem is identified: situation A; 2 A final goal, or solution, is imagined and described: situation $B$; and 3 The act of design is the causal link by which situation $A$ is transformed into situation B.

A new logical structure of the design process is: 1 Instead of a problem, we have: state A of a system; 2 Instead of a solution, we have: state B of the system; and 3 The designer and the user are part of the system (stakeholders). (Findeli, 2001, p. 9)

In this approach, as Findeli concluded, Schön's theory (1987) of "reflection-in action" stops being only a methodology and is moved into the epistemological realm. Hence, Findeli explained that, in the process of affecting systems, a designer or client cannot act upon a system, only within a system. To do that, learning plays a critical role. He posited the notion that a designer learns the relationships, dynamics, and patterns inside the system. Clients, users, and designers, together through a certain set of values, transform themselves and the system. State B is accordingly a transitory, impermanent, state of the system that can be called "solution."

In many ways, Findeli's synthetic logical structure of design assimilated Simon's analytic one. This was done by encompassing multiple dimensions of design research instead of focusing on a particular one, such as the generation of artificial entities, which could, in this new structure, be understood as subsystems. These dimensions included the objects of design inquiry, but also the objects of design knowledge. Accordingly, design inquiry involves object as artifact, process, and stakeholder, which are equally important for different aspects of design: object for aesthetics, process for logic, and stakeholder for ethics (Findeli, 2010). Yet, Findeli's logical structure did not exclude functionalism, which was moved into the social domain, giving the designer the function of a change inducer in the system. In Findeli's logical structure, the idea of change of the artificial was redirected toward change of the social through reflective practice. By losing the link between artificial and social, or artifact and stakeholder, in the very core of design conception and reception, Findeli was at risk of making another functionalist model, this time a social synthetic one. When it came to design knowledge, Findeli called for encompassing the issue of reception by the stakeholders as a second knowledge dimension of a design project (Findeli \& Bousbaci, 2005). This is a very important idea, as the unpredictability of reception of design by stakeholders can induce emerging new relations among the stakeholders. In the following case study, a selected representative case of practice-oriented design education in assistive technologies revealed the emergence of these relations through technology.

Still, it is remarkable how the inheritance of the problem-solution functionalist paradigm from Simon's (1976) technical rationality has tended to endure as a conceptual construct through the years of discourse and changes that have occurred in the design discipline. I therefore agree with Findeli's observations about the need to define design in different terms. There were serious attempts however to do this through many years of design debate. Schön (1985) explained how practitioners are not 
solving problems, but rather performing their practice routinely. When practitioners enter an indeterminate zone of practice, they start reflecting in action and on action. Krippendorff (2006), similarly to how Findeli focused on reception, saw design in terms of how design is interpreted by the receivers rather than how it is intended to function by the designer, which I will address later in the findings section. The focus on the design as a mental process by stakeholders in a design situation, especially on the designer, is perhaps best exemplified through the concept of "design thinking." This concept was first conceived by Rowe (1987) but became widely accepted by the design community as a way of not only bringing into being material artifacts but also dealing with complex problems, thus moving design into the field of management. This can be seen in the explanation that design emerges as a bridge between an evolving abstract problem and solution spaces as designers learn about the design topic they work on (Dorst \& Cross, 2001). Finally, even pragmatic attempts to define design as liberal arts that operate in multiple dimensions - signs, things, actions and thoughts - are seen through design thinking applied to different logical modalities in different fields (Buchanan, 1992). In this short and rather basic overview, it can be seen that the discussion moved from the procedural issues of designing toward design as a psychological activity of the stakeholders. This seems to be ontologically challenging if we are to understand design as a process that encompasses processes, artifacts, and stakeholders, as Findeli proposed.

There is, however, clearly a movement toward Findeli's logical design structure, especially in the context of design for sustainability. In this paradigm, economic imperatives are moderated to adapt to sustainability imperatives, while designers operate on product, service, organizational, and societal levels dealing with socio-technological systems (Ceschin \& Gaziulusoy, 2016). Although system theories provide valuable contributions to designers to understand the intention of their actions in a holistic way, I would advise caution in ascribing system theories as the explanation of the design phenomenon itself. The reason for this is that system theories are varied and somewhat incoherent in their approaches as they differ ontologically. When applied in natural sciences, systems theories rely on realism where the system is defined by a closed loop, which secures scientific rigor (Laszlo \& Clark, 1972). In social sciences, it is perspectivism as an ontological stance that is dominant in systems theories, where the boundaries are not clearly and permanently defined but rather fluid and constructed as they are needed. This means that the constitution of the system is rather a perspective of the observer (Midgley, 2000). This ontological position, especially in social sciences, is problematic as it ascribes totalistic and organizational views on the design situation from a certain perspective. It is therefore difficult to take advantage of systems theories, which are already criticized for being technocratic and difficult to apply in their totalistic approach. This is because the stakeholders, by being the part of the system, are not able to see the whole picture, but are rather certain parts of the design situation from their own perspectives (Hammond \& University of California, 1999). To deal with this situation, Findeli (2001. p. 12) recommended a "phenomenological, qualitative approach as best to understand the systems within."

\section{Design situation: socio-technological configurations from within}

To deepen the understanding of how designers and clients learn the relationships, dynamics, and patterns inside the system, it might be more helpful to discuss design from what is phenomenologically observable to these stakeholders. That is not designers' thinking, or holistic chains and loops emerging in the system but, as Findeli pointed out, inter-relations that come into being when stakeholders are interconnected. One aim of this article is therefore to deepen and expand Findeli's ideas in two ways. First, to examine designing and learning as phenomena occurring through relations within what Findeli characterized as a system (2001). A second is to take the discussion on Findeli's logical structure of design in a new direction so that it becomes more empirically attainable for designers and learners. To do this, the design community should perhaps consider looking at designing as a series of relationships. By following this relational ontological approach, perhaps some theories relying on this ontology could generate a new approach that is neither functionalist, constructivist, nor systemic. Some of these theories are actor network theory, new materialism, or agential realism. In this article, however, I will focus on postphenomenology as an initial step to take into consideration relations emerging between 
the stakeholders and the technologies they use. The goal of breaking down the design process from the perspective of postphenomenology is to provide a insights based on this relationalist approach. Further, the intention is to reopen the issues of designing from the position of the philosophy of technology, which has become of increased interest along with emerging technologies such as 3D printing. The expanded understanding of these concepts will be fed back into the discussion on design education that Findeli has opened and shed a different light on designing and learning to design.

\section{METHOD: RELATIONAL ONTOLOGY, CASE STUDY, AND POSTPHENOMENOLOGY}

The object of my research, therefore, was to investigate the relation among humans and between humans and their artifacts. The methodology for studying this relied on different ontological premises to those of conceptualizing design as a psychological activity or an individual perspective of what constitutes a system. Ontology is the branch of philosophy that inquires into the nature and structure of "reality." To be concise, I have used Gruber's (1993) definition in which ontology is described as "an explicit specification of a conceptualization." In other words, ontology is what is conceptualized and concerned as an existing entity. For Descartes, mind and matter were viewed as two finite substances, signalizing ontological dualism (Rozemond \& Rozemond, 2009). By conceptualizing that design happens in the mind of a designer which is separated from designers' natural or technological environment, such as, for example, in the concept of "design thinking," a researcher or design theoretician builds a very particular understanding about designing. To address the issue of relations between stakeholders and their environment, this article takes a relationalist ontological position. "The basic contention of relational ontology is simply that the relations between entities are ontologically more fundamental than the entities themselves" (Wildman, 2010, p. 1).

Relationalism has been explored by phenomenologists beginning with Heidegger, who denounced Husserl's understanding of Cartesian mind-body split. Phenomenologist Merleau-Ponty (1996, p. 456) took this further and explained relationalism in this way: "man is a network of relations," in that, humans are interdependent with the objects surrounding them. For him, humans are not fully transparent to themselves, and objects are given over to us, influenced by us, just as we are influenced by the objects that surround us. Learning as a precondition for any change is explained as bodily situated and therefore happening in relation to the environment. Merleau-Ponty (1996, p. 164) claimed that physical and social embodiment shapes meaningful learning. Embodied learning means that human bodily capacities, such as those that are mental, emotional, and physical in relation to environmental affordances and constraints, are the preconditions for learning. The focus here is therefore on the relation between environment and learner and the connection they establish that changes them both. Accordingly, learning is a process in which previous knowledge allows participation in embedded situations. Each next learning modifies the entire horizon of experience and expertise. Learning means to change and transform oneself or, as phenomenologists call it, being and becoming.

Idhe and Malafouris took these ideas to explain human-technology and human-material relations in an evolutionary sense through postphenomenology and material engagement theory. Accordingly, the relationship between humans and technologies as well as the materiality of the human environment are inter-transforming and make each other. "Homo faber refers to the special place that this ability has in the evolution and development of our species," in the words of Ihde and Malafouris (2019, p. 195). Verbeek (2016) effectively incorporated postphenomenological ideas in his mediation theory. He posited that the relation between humans and their environment is therefore mediated by technology, not only in the sense of what things do, but what kind of meaning humans give to technologies both empirically and conceptually. Through mediation theory, Verbeek described mediation as the ability of technology to enhance human perception and action in one way and prohibit it in the other, which also includes effects of cultural practices. He supported his mediation theory with ideas earlier developed by another group of researchers who derived their thinking from metaphysics, namely Akrich and Latour (1992). In their view, technological artifacts present a script that proposes their use in a certain way. Accordingly, designers delegate specific responsibilities to artifacts. For 
example, the responsibility that drivers do not drive too fast in populated areas is delegated to speed bumps. Thus, the relationship between objects and humans is reciprocal (Ihde \& Malafouris, 2019).

The other set of postphenomenological concepts deriving from cognitivist science is also important if we are to understand mediation between humans and technologies (Rosenberger \& Verbeek, 2015). These concepts include transparency, multistability, and virtual action. Transparency is a phenomenon in which, after excessive use of technologies, humans become accustomed to the mediating properties of these technologies. Multistability is a phenomenon in which technologies reveal themselves in human experience as the result of the users' previous experience and context in which they are used and can therefore change their function and meaning. Virtual action is a phenomenon in which humans can contemplate their activities as mediated by technologies even if those technologies are not present in the human site (Kiran, 2012). These concepts will be further explained and developed throughout this article.

\section{Instrumental case study}

To depict and expound on how designing, including its conception and reception process as well as objects, and stakeholders manifest themselves, I tracked them as units of analysis throughout a case study of design studio learning with assistive technologies. The case study methodology was chosen as a means to investigate the phenomenon of design inquiry and knowledge in a real-life context, namely, design studio, especially as the boundaries between these abstract concepts and real-life design learning are not clearly defined (Yin, 2017, p. 15).

This research followed the logic of an instrumental case study (Stake, 1995, pp. 63-66), where usual or typical cases are selected to generalize from them in an inductive manner. This research method is based on broader philosophical underpinnings and often concludes with contributions and changes to them. This means that the case itself becomes an instrument for studying a phenomenon. In an instrumental case study, participants and the setting are not necessarily the focus of the study; instead, it is a phenomenon that is very well represented in the studied setting. In this case study, the studied phenomenon was the manifestation of the logical structure of design that Findeli brought into focus. In this way, the object of the study was socio-technological relationships, or as Findeli named them, artifacts and stakeholders, as well as processes, specifically the ones of conception and reception.

Postphenomenologists often employ micro-scale case studies because they allow them to investigate the relationship between humans and technology as well as how instances of technologies inform individuals' choices, actions, and experiences in the world (Rosenberger \& Verbeek, 2015, p. 10). This study was therefore conducted as a representative or common single case. The case was typical because it represented a typical praxis placement for design students. It included primary and secondary users, the team of design students, and academic staff. It was also typical, as it could have been considered a typical product design project, where the task posed to the design team was to develop a personal assistive technology product from their research of the patient's needs.

The case study was situated in the learning site of a four-week course in assistive technologies in international cooperation between Oslo Metropolitan University and the University of Sao Paulo, and included a local rehabilitation center, Sorri in Bauru its staff, patients with various disabilities, and their caregivers. The experience reported here is part of an international collaboration between institutions from Norway and Brazil on the research and development of assistive technologies (Sandnes et al., 2017). The study followed a team of three students and the process of design.

The learning setting was organized around the assumption of minimum pedagogical intervention to simulate a design practice context in the best possible way. The process therefore did not include the critique about design choices between students and teachers. The assessment relied both on how students were able to observe a design situation and the way they were able to address it. The discussions and decisions were entrusted to the network of participants, who were expected to propose a design through consensus. In addition, the theoretical input to the students were introduced through lectures and the literature. This included lectures on assistive technologies, ethics in interviewing patients, and general prototyping strategies. The students did not have previous 
knowledge or skills with 3D printing or assistive technologies. Students had a wood, metal, and 3D print lab at their disposal.

The method relied on participatory observation, audio recordings, and student reports. The researcher was also a guest lecturer on the subject of prototyping strategies. This put the researcher in an outsider position as he was not part of the network creating the design or grading students' work. Yet, the students were desensitized to the researcher's presence due to the lecturer role. Often, the researcher is therefore an outsider to the student group (Herrmann, 1989), but an insider in the research field, which presents disadvantages, such as a lack of objectivity and making false assumptions (Delyser, 2001). This is especially emphasized in the way researchers focus on prototyping tools and technologies. This was mitigated in my study through a clear theoretical framework and triangulation to support the validity of the claims. Further, participants were asked to give their opinions on the findings, as a means of seeking consensus on understanding what happened throughout the course of the research.

To guarantee the ethical standards, the research was granted authorization by the Norwegian Council for Research Data according to the ethical standards that include participant consent, anonymization, and secure data handling. Patient involvement was organized through informed consent, confined to the space of the Sorri, limited in time, and monitored and led by therapists. The other ethical issue was managing patients' expectations, which was mitigated through patients' discussion with therapists. The social and clinical value was in understanding how academic cooperation and research could contribute to customizing assistive technologies for patients. The ethical standards for patients were insured through previously agreed upon general terms between the University of Sao Paulo and Sorri.

\section{FINDINGS: RELATIONSHIPS UNFOLDING THROUGH DESIGN PROCESS}

Visiting the rehabilitation center, the student group met a 29 -year-old male patient. The patient was paying weekly visits to the center for rehabilitation to regain control over the left side of his body, which had been paralyzed by a stroke. The stroke, he claimed, had caused significant changes in his life. Even though he was right-handed, after the stroke he could not continue his work as the owner of a local farm. Throughout the meeting, he was struggling to walk and grip with his left hand. Still, he remained positive. The group of students interviewed him to gain insight into his perspective of the condition. After the meeting, the therapists shared an understanding of the recovery process from their perspective. They stated that they were satisfied with his recovery, but that the process would have been more fruitful if the patient had been more persistent in using his limbs rather than finding workarounds by employing the functioning side of his body. This directed the group to discuss how to engage the left side of the patient's body. After the stroke, the patient's left hand was frozen in position of a permanent half-grip, disabling it for use in ordinary activities.

\section{Conception of design}

From the start, the student team focused on what for them was the most obvious issue: "The user's hand is the most obvious problem, even though he doesn't explicitly complain about it." This led them to consider augmenting the opening of the patient's hand so that he could perform a gripping motion. Early in the process, the team produced a mock-up made of tape, paper, and thread, which illustrated but could not perform the grip opening function. To do this, they had to revisit the patient and take measurements of the patient's hand. They designed the prototype in detail using modeling software, which allowed them to define the shape and size of the rings, as well as thread openings (Figure 1). They 3D printed a series of finger caps and rings in different sizes for each finger. The prototype of the dynamic orthosis was designed to open the hand by pulling a nylon thread.

At the beginning of the project, the team discussed the potentialities of the 3D printing technology. Through a series of meetings, they decided to focus on designing and customizing an orthosis to meet the patient's needs. The geometry, the size of the rings, and parts' features were initially difficult to form. After the first ring was 3D modeled, they discovered that they could copy it and 
easily alter dimensions for the rest of the rings using the parametric settings in the software. Further, they struggled to position the ring in the 3D print preparation software, also known as slicer, so that the plastic, referred to as the part support, did not fill the holes as it was difficult to remove once the print was done. After the first two failed attempts, they found a solution, and the technology became more transparent to them, meaning the outcomes of their attempts became more predictable. As they got used to 3D printing, they were able to focus on how to utilize the minimum plastic thickness setting of the 3D printer to make the rings more elegant. It seemed as if they had adopted the 3D printer as a tool. Finally, by transforming their mock-up into a virtual model, their experience of the design situation changed, and the task became more manageable as one of the students noticed: "We would never be able to make this complex prototype in such a short time without a 3D printer." Thus, they had adapted $3 \mathrm{D}$ printing for their purpose of producing customized parts for the needs of an individual patient.

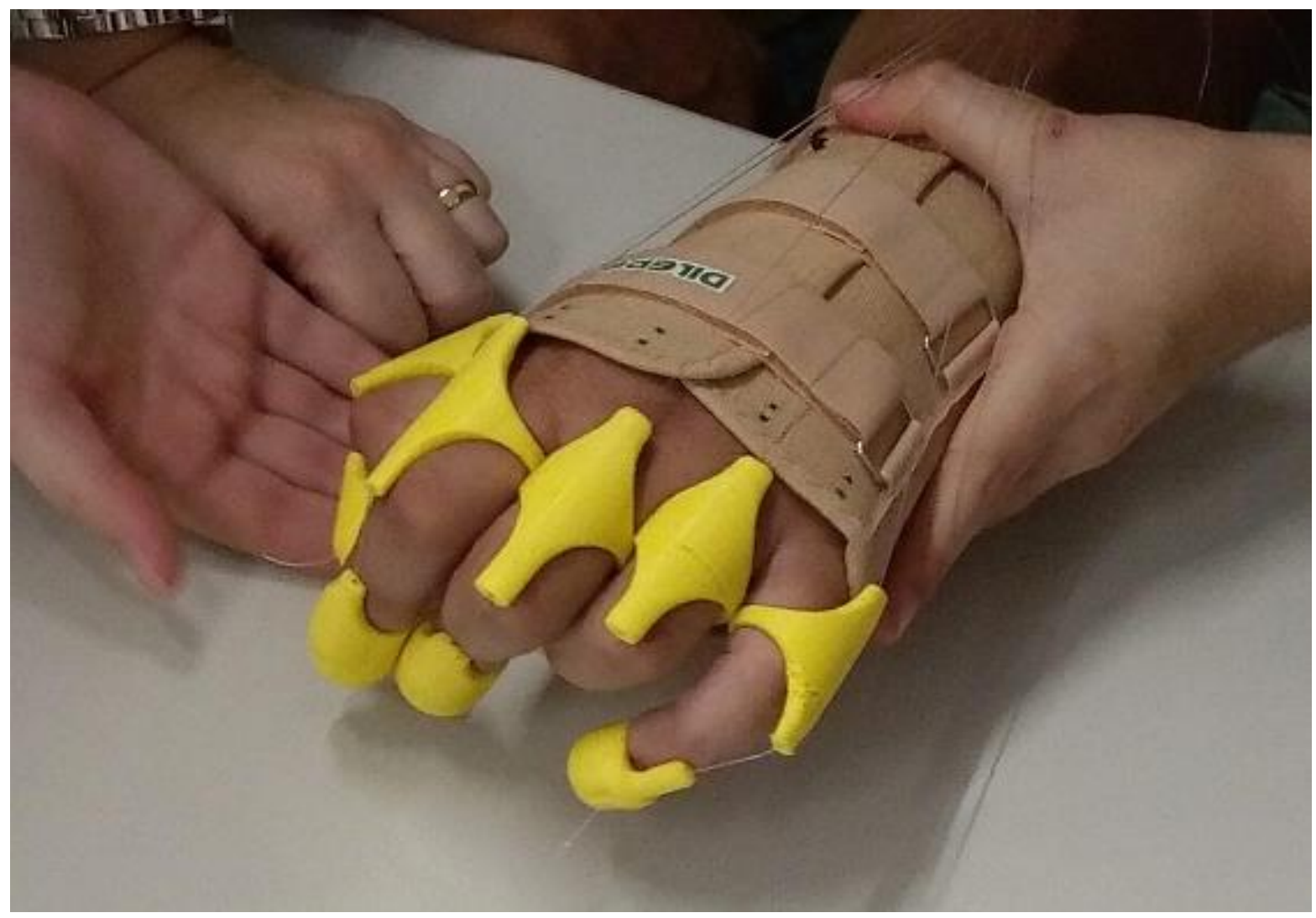

FIGURE 1: The assembled dynamic orthosis was tested with the patient. Photo by Nenad Pavel.

\section{Reception of design}

The team assembled the prototype directly on the patient's hand, fitting the rings on the fingers. They demonstrated the hand opening principle with their prototype (Figure 1). The therapist noticed that the dynamic orthosis was functioning quite well, as it was effective in pulling the patient's fingers backwards in a cascading motion, the tip of the fingers first. The students explained that further refinement of the prototype would include the development of a dynamic mechanism for opening the hand that would be attached to the elbow motion. As the students were mounting the dynamic orthosis prototype, they noted: "He doesn't seem to be commenting on this as he did before." Also, the therapist observed: "It will be difficult for me to convince him to use this outside of the hospital." In further conversation, it became obvious that this did not necessarily have to do with the functionality of the prototype. It seemed to be more about how this orthosis and its use would make the disability explicit to the patient and potentially to his environment as well. 
This shows how the students failed to fully comprehend the way the technology mediated their experience. For the user, the assistive technology emphasized his ability to open the hand but also amplified his awareness of his immobility and the possible stigma associated with using the technology. Moreover, the technology was not possible for him to adapt for his purposes, as he could not see the value of it in his already established routines where he used compensation strategies. These strategies relied on using his knees to grip objects and his right hand to manipulate them. Therefore, he failed to utilize this technology from its potentiality to its actuality. However, the therapist recognized a purpose for this object: "I think we could use it as a part of the gripping exercise that we already do." In her understanding of its value, when fully functional, this assistive technology could be sedimented into her work practice. The therapist was able to visualize the actual usage of this technology.

\section{Postphenomenological view of the described case}

This case study illustrated a particular design learning setting limited in its technologies, stakeholders, and processes. While these limitations did present an opportunity to track relations between the participants and artifacts in detail within the scope of this article, they only allowed for obtaining a very narrow outlook into what design is in practice. Thus, further research is needed to study how the concepts proposed in the following sections of the article could be understood in other design settings. In service design projects, for example, touchpoints often have material and technological qualities that can be overlooked by designers focusing on the social aspects of the service. In design for sustainability projects, technological solutions are often the cause of the challenge and sometimes a solution. Consequently, understanding how humans learn technologies is of importance. Furthermore, research in informatics design projects might provide an alternative to functionalist explanations of design, especially in the way the designing medium, such as coding language or the hardware-software relationship, is arranged.

That said, let us consider the case study presented. Here, it can be seen how the process of designing occurs when all the stakeholders are included, not only the designers. In this case, the conception of design was dependent on designers' process of adoption of the 3D printer and its operational capabilities. Next, they adapted the 3D printer for the purpose of producing parts for the orthosis, temporarily stabilizing 3D printers as a prosthetic production tool. Finally, they were able to apply the specific functions of the 3D printer to achieve the complex geometry that this type of orthosis demands. It is important to note here that the reception of design also follows the process of learning through technology. The patients and therapists can use the dynamic orthosis prototype, and the therapists can adopt it for their own practices. In this case, the patient abandoned this technology because it was not sustainable in his everyday practice, but the therapist adopted it in her own therapeutic practice. What is perceived as a creative act of designers, in a postphenomenological sense, can be described as a temporary resolution of tension between technological scripts and technological multistability, which designers stabilize in conception and users in reception of designs. The result is that the artifacts are not defined only, sometimes not at all, by the designers' intentions, but by the users' ability to adopt the technology for a meaningful practice using them. In the case study, designers were not expecting that the orthosis would be used by the therapist instead of the patient, which modified the therapeutic service for this patient instead of his daily routines.

The very technological medium itself that designers use to design can make an impact on design solutions, but also on learning, which happens in educational situations. In this case study, by deciding to use 3D printers, the design learners in the study might have overlooked other stakeholdertechnology configurations. The medium they happened to use directed them to utilize 3D printers' capabilities to produce complex geometry and go for a solution that addressed the most significant perceived issue, the patient's immobile arm, but in an unacceptable way for the patient. Perhaps, if they had not been able to utilize the 3D printer for advanced geometry, they might have discovered and addressed some particular situation in the patient's daily routine that would be more meaningful to the patient, and might have tried to adjust his technological environment instead of his technological body. In the reception of design, the unfolding learning reveals stakeholder intentionalities and power 
domains. It shows how the students lack insight into the patient's perspective and rather approach normalization of his body as a strategy for their design of the assistive technology.

The medium has also influenced what the design students learned in their assistive technology course. By being able to attain high-precision complex parts in a short period and through only one production process, they were able to address the practical issues of medical orthosis design. Thus, the $3 \mathrm{D}$ printer mediated their learning in many ways. First, it diminished training time because the students did not have to use a series of machines, but also avoided the safety training needed to operate these machines. Second, the complex geometry of orthosis revealed students' intentionality in the project in a more sophisticated way, mediating their knowledge about design and ergonomics in respect to the teachers. Finally, the student group learned how to design, not from the critique of their teachers, but from the involvement and response within their socio-technological environment. In other words, the learners had a chance to exercise their agency through utilizing technology and experiencing the impact they made or failed to make on other participants in the project.

\section{DISCUSSION: DESIGNING AND LEARNING DEMANDS, STAKEHOLDERS, PROCESSES, AND OBJECTS}

Following the logic by Ihde and Malafouris (2019) that the relation between humans and technologies as well as materiality are inter-transforming and make each other, I propose a different framework for explaining designing and learning. In this framework, the processes that Findeli singles out as the crucial philosophical dimensions of designing are understood as artifacts and stakeholders that are intertransforming their environment. In this process, stakeholders develop practices around artifacts. Learning and designing can therefore be described as an outcome of a series of mediations among stakeholders by the means of the technologies they are interacting with.

Learning through technological mediation can be described by postphenomenological concepts of human-technology relations. I therefore propose a framework for learning as a configuration of human-technology relations that happens through adoption, adaptation, attainment, and abandonment of technologies.

Adoption happens through human bodily interaction with technology. In adoption, users of a technology find out about technology's pervasiveness. As they are able to achieve expected results in routinized use, the technology becomes transparent. Building on Heidegger's (2010, pp. 82, 83) explanation of the "manipulability" of technologies, postphenomenologists explain that users become immersed in technology until they stop noticing it at all. "My glasses become part of the way I ordinarily experience my surroundings; they 'withdraw' and are barely noticed, if at all. I have then actively embodied the technics of vision," as Ihde noted (1990, p. 73). He also emphasized that, similarly, when technology malfunctions, it becomes suddenly noticeable just as when, once the parts of our body hurt, they become the center of the attention. If the technology is not usable, it is opposite of transparent and can be called opaque. Learning can be understood as the level of this embodied familiarity of a learner from opaque to transparent.

Adaptation happens as humans emotionally and perceptually engage with and recognize technologies' usefulness for their own purpose or social context. Humans determine how meaningful this technique is for their causes, and for which causes it can be used. The concept relies on MerleauPonty's (1996) ideas of human perception. Accordingly, humans see the whole through attaching the meaning to the object they perceive, rather than seeing parts and connecting them to construct a whole. This phenomenon is called multistability and is explained by cognitive science, for example, in a way the optical illusions allow us to interchangeably give different meaning to the figure we see. Postphenomenologists attach this phenomenon to technologies as they change their meaning and function through different cultural and functional contexts. For example, "a bottle mediates pouring liquid but also holding a flower" (Rosenberger, 2009, p. 175). The more a technology is used in one way, the more it becomes part of certain practice and becomes sedimented in human activities.

Attainment happens through human mental processes used to contemplate technologies' usages and applications. Technology therefore changes human behavior and actions even though it is not in users' vicinity (Kiran, 2012). This means, according to Kiran, that technology influences the 
lifeworld not only through its actuality but also in its potentiality. For example, "A mobile phone resting in your pocket is virtual communication; it can be utilised to realise the action of talking to a friendtalking to this friend is actualized communication. Each such role, in its state of possibility, can be called a virtual action" (p. 78). Learning happens as humans are able to virtualize the potentialities of certain technologies and therefore become augmented by their affordances.

Abandonment happens as humans find out alternative ways to achieve their goals by considering other technologies. Technologies are abandoned when they no longer allow for sustainable practices, or they are simply replaced by the more efficient or meaningful technology for the same practice.

\section{Relationalist logical design structure}

Design is the reconfiguration of the human-technology relationship that occurs through the conception and reception of design. Both conception and reception imply learning through technological mediation, including adoption, adaptation, and attainment. In design conception, the outcome of learning is new artifacts. In design reception, the outcome of learning is new practices.

These reconfigurations include changes in stakeholders' practices and sometimes their identities. For example, by learning the technology of 3D printing, students could become designers, while patients using assistive technologies could become survivors. By learning and integrating technologies into their practices, stakeholders are being and becoming. They are succeeding to a certain extent or failing to adapt technology in their new practices, thus achieving or failing to attain their intentionalities.

In this framework of learning and designing, the design is not a way of thinking coming from the head of designers, or an intervention in the system; it is the result of homo faber's capacity to modify and be modified by the environment. As technology has become a significant factor in all aspects of the human environment, learning is determined by the prohibitions and enhancements of human abilities by the means of technologies and social practices enveloping them. The logical process of design structure might not be described as a system transformation from state A to state B but as the development and reconfiguration of stakeholder relationships through technological mediations, such as the following: 1. In state A stakeholders are perpetually engaged in designing, meaning reconfiguration of stakeholder-artifact-stakeholder relations; and 2. In state B, the beneficial configurations are temporarily stabilized before either the stakeholders, artifacts, or processes are altered.

The design is therefore an outcome of the way designers relate to their socio-technological environment through the design medium in design conception as well as the way users relate to their socio-technological environment through a newly designed artifact in design reception. The relationalist postphenomenological perspective on designing shows how processes, artifacts, and stakeholders are inseparable.

This approach also illustrates how the creative process is closely related to the medium. Design competence in the postphenomenological sense relies on designers' learning about their own medium artifacts in conception and affecting socio-technological practices through designed artifacts in reception. To do this, designers are challenging scripts and sedimented uses of artifacts, both of their own medium and those used by stakeholders. The new practices emerge in adaptation through multistability relations by both designers and stakeholders. Perhaps designers' creativity can be seen from this perspective as a temporal suspension of judgment when observing socio-technological practices. This temporary suspension of judgment, also called bracketing (Hamill \& Sinclair, 2010), can enable escaping the script that the technology imposes, halting sedimented practices established with the technology, or abandoning the given technological medium and adopting another.

\section{Implications for makerspace and design studio}

From the postphenomenological perspective, our understanding of design inevitably brings us back to the philosophy of technology. However, this time, it is done from the perspective of humanities, rather than that of an analytical-instrumental branch of this field. Objects or artifacts are still present and as important as they ever were in the design process. But we should perhaps not look at them through 
functionalism as artificial entities, as proposed by Simon (1969). In the age of rapid technological advancement, they appear as scripts disguised as codes steering interfaces on the many screens we rely on in our daily environment. As services, they may now be withdrawn from our awareness, becoming ever more transparent and difficult to identify. The materiality of design is now possibly an integral part of a service. Therefore, we should account for technological artifacts as our natural environment. In fact, it is the only environment possible due to the evolution of the human-technology inter-relation. In fact, instead of asking what is natural and what is artificial, we should ask what is sustainable and what is not. Further, we should not dismiss material and technological artifacts as instruments, fully controlled by stakeholders' intentions, with a totalistic view of them as parts that create a whole. We should rather look at how they co-constitute the design situation and how they co-constitute the stakeholders' actions and the design process.

The equal importance of stakeholders, objects, or artifacts and processes can be used to establish the way design education is treated. Traditional education puts content knowledge at the center of educational efforts. Newer pedagogical forms are putting learners at the center and regarding learning as a change in the behavior of a learner (Holt et al., 2015). Some theories promote the importance of the social, such as social constructivism, but most seem to disregard the importance of the material and technological factors.

Design theories follow a similar pattern. Technical rationality puts functionalism in the focus, defining the man-made world as a set of artifacts designed by humans to satisfy their needs (Simon, 1969). Constructivism puts humans and the conception of design in the focus. Schön (1987) considered design to be action and reflection from the perspective of a designer. Systems theories are diverse, but the focus is on design as an intervention inside the system based on certain principles. Relations are recognized among the parts that are organized in a manner to accomplish a common purpose (Buchanan, 2019). Design methods based on systems thinking rely on the premise that designers should be able to recognize leverage points and define a potential intervention inside the system. Some design studio education has started developing in the direction of consultancy and management, where design thinking and problem framing by using theoretical design methods is a main focus (Kimbell, 2011).

In the relational ontological view, however, this is challenging because not only are designers part of a system, they also co-constitute the design situation. Designers are not looking at the design situation objectively from above. The design situation therefore comes into being and unfolds through intentionalities and relations between the designer and other stakeholders as well as the artifacts. The designers do not critically reflect outside of the context they inhabit. The designer is rather defined by the relations she develops with stakeholders and artifacts. Relationalism does not explicitly imply that a designer is a part of a system that is put together with other parts to accomplish a common purpose in feedback loops.

It is therefore the position in the socio-technological configuration that the designer has which determines the intentionality she exerts. To achieve systemic intervention, designers must relate to the socio-technological arrangements on the levels of organization and society, or else their design risks losing its iterative and empirical character. The challenges may occur in educating designers on the principles of design thinking, as in some design schools the constructivist learning approach to education is used. Here, a group of students might be put together to learn how to design through discussions and the collection of declarative knowledge about the design topic. However, these discussions can end up in post-it notes and synthetic map posters (Jones \& Bowes, 2017), without students necessarily seeing the effects of their assumptions in socio-technological configurations. Even in the case when synthetic maps are used among participants that can influence reality, the relationalist perspective would demand critical assessment of a design medium, such as a synthetic map that can enhance a certain understanding of the design situation and prohibit another, urging a less managerial, totalistic, and more phenomenological contextual approach.

At the same time, the makerspace as a type of informal education has a strong focus on materiality and technological artifacts. "Makerspaces are informal sites for creative production in art, science, and engineering where people of all ages blend digital and physical technologies to explore ideas, learn technical skills, and create new products," according to Sheridan et al. (2014, p. 505). They 
are a direct result of the maker movement, which is known for organizing informal learning spaces where enthusiasts gather their digital tools and knowledge to launch their individual projects (Dougherty, 2012). In makerspaces, learning is autonomous, self-driven, and self-motivated, so what and how it is learned is decided by peers and their sense of what is interesting and fun (Petrich et al., 2013, p. 65).

In the relational ontological view, this is also challenging, as both conception and reception happen among the same stakeholders. While learning in an isolated group provides a safe space for experimentation, it misses on multi-vocality of stakeholders which can provide different adaptations and attainments for designed artifacts. This can lead to technologies defying their own societal purpose.

To conclude, the relationalist view in design advises that students must be educated to be aware of their own agency, ability, and responsibility to influence the socio-technological environment. Only through being educated in externally interconnected design studios can they become responsible, critical, and resilient to rapid technological and social changes. This demands design education to enable access to the practice where the design process can come into being, instead of splitting design into thinking and doing. For educating relationalist learners, it is necessary to have a fluid link between academia and society. Relationalism in design reminds us that stakeholders participating in the design process co-constitute the environment they inhabit. It strips the abstractions that appear in the complexity of design topics of today and defines design as a generalist discipline. In this view, it is difficult to split ideation and investigation, conception, and reception. It gives primates authentic phenomenological and empirical participatory inquiry instead of declarative knowledge, isolated tinkering with technology, or design as knowledge labor. It focuses on critical and diffractive practices with design media, which is possible only through a hands-on approach. Twenty years after Findeli's article, instrumentalism might still be dominant. However, the very complexity of the design topics has led the design process to become fragmented, and designers have specialized in particular parts of it. Perhaps, lifelong learning oriented education system could effectively support generalist designers who can adapt to the emerging technologies and changing social environment. 


\section{REFERENCES}

Akrich, M., \& Latour, B. (1992). A summary of a convenient vocabulary for the semiotics of human and nonhuman assemblies. In J. L. Wiebe \& E. Bikjer (Ed.), Shaping technology/ building society (pp. 92-97). The MIT Press.

Buchanan, R. (1992). Wicked problems in design thinking. Design Issues, 8(2), 5-21.

Buchanan, R. (2019). Systems thinking and design thinking: The search for principles in the world we are making. She Ji: The Journal of Design, Economics, and Innovation, 5(2), 85-104. https://doi.org/10.1016/j.sheji.2019.04.001

Ceschin, F., \& Gaziulusoy, I. (2016). Evolution of design for sustainability: From product design to design for system innovations and transitions. Design Studies, 47, 118-163. https://doi.org/10.1016/j.destud.2016.09.002

DeLyser, D. (2001). "Do you really live here?" Thoughts on insider research. Geographical Review, 91(1-2), 441453. https://doi.org/10.2307/3250847

Dorst, K., \& Cross, N. (2001). Creativity in the design process: Co-evolution of problem-solution. Design Studies, 22(5), 425-437.

Dougherty, D. (2012). The maker movement. Innovations, 7(3), 11-14. http://www.mitpressjournals.org/doi/pdf/10.1162/INOV_a_00135

Findeli, A. (2001). Rethinking design education for the 21st century: Theoretical, methodological, and ethical discussion. Design Issues, 17(1), 5-17. https://doi.org/10.1162/07479360152103796

Findeli, A. (2010). Searching for design research questions: Some conceptual clarifications. In R. Chow, W. Jonas, \& G. Joost (Eds.), Questions, hypotheses \& conjectures: Discussions on projects by early stage and senior design researchers (pp. 278-293). iUniverse.

Findeli, A., \& Bousbaci, R. (2005). The eclipse of the object in design project theories. The Design Journal, 8(3), 35. https://doi.org/10.2752/146069205789331574

Gruber, T. R. (1993). A translation approach to portable ontology specifications. Knowledge Acquisition, 5(2), 199-220.

Hamill, C., \& Sinclair, H. A. (2010). Bracketing-practical considerations in Husserlian phenomenological research. Nurse Researcher, 17(2). https://doi.org/10.7748/nr2010.01.17.2.16.c7458

Hammond, D. R. (1999). Toward a science of synthesis: The heritage of general systems theory. UMI Research Press.

Heidegger, M. (2010). Being and time. SUNY Press.

Herrmann, A. W. (1989). The participant observer as "insider": Researching your own classroom [Paper presentation]. Annual Meeting of the Conference on College Composition and Communication, Seattle, WA.

Holt, N., Bremner, A., Sutherland, E., Vliek, M., Passer, M., \& Smith, R. (2015). Psychology: The science of mind and behaviour. McGraw-Hill Education.

Ihde, D. (1990). Technology and the lifeworld: From garden to earth. Indiana University Press.

Ihde, D., \& Malafouris, L. (2019). Homo faber revisited: Postphenomenology and material engagement theory. Philosophy \& Technology, 32(2), 195-214. https://doi.org/10.1007/s13347-018-0321-7

Jones, P., \& Bowes, J. (2017). Rendering systems visible for design: Synthesis maps as constructivist design narratives. She Ji: The Journal of Design, Economics, and Innovation, 3(3), 229-248. https://doi.org/10.1016/j.sheji.2017.12.001

Kimbell, L. (2011). Rethinking design thinking: Part I. Design and Culture, 3(3), 285-306. https://doi.org/10.2752/175470811X13071166525216 
Kiran, A. H. (2012). Technological presence: Actuality and potentiality in subject constitution. Human Studies, 35(1), 77-93. https://doi.org/10.1007/s10746-011-9208-7

Krippendorff, K. (2006). The semantic turn: A new foundation for design. Taylor \& Francis.

Laszlo, E., \& Clark, J. W. (1972). Introduction to systems philosophy. Gordon and Breach New York.

Merleau-Ponty, M. (1996). Phenomenology of perception. Motilal Banarsidass Publishers.

Midgley, G. (2000). Systemic intervention. In Systemic intervention (pp. 113-133). Springer.

Petrich, M., Wilkinson, K., \& Bevan, B. (2013). It looks like fun, but are they learning? In M. Honey (Ed.), Design, make, play: Growing the next generation of STEM innovators (pp. 50-70). Routledge.

Rosenberger, R. (2009). The sudden experience of the computer. Al \& Society 24, 173-180. https://doi.org/10.1007/s00146-009-0190-9

Rosenberger, R., \& Verbeek, P.-P. (2015). Postphenomenological investigations: Essays on human-technology relations. Lexington Books.

Rowe, P. G. (1987). Design thinking. The MIT Press.

Rozemond, M., \& Rozemond, M. (2009). Descartes's dualism. Harvard University Press.

Sandnes, F. E., Medola, F. O., Berg, A., Rodrigues, O. V., Mirtaheri, P., \& Gjøvaag, T. (2017). Solving the Grand Challenges Together: A Brazil-Norway Approach to Teaching Collaborative Design and Prototyping of Assistive Technologies and Products for Independent Living. In A. Berg, E. Bohemia, L. Buck, T. Gulden, A. Kovacevic, \& N. Pavel (Eds.), Proceedings of E\&PDE 2017 - International Conference on Engineering and Product Design Education. Building Community: Design Education for a Sustainable Future (pp. 242247). The Design Society.

Schön, D. A. (1985). The design studio: An exploration of its traditions and potentials. International Specialized Book Service Incorporated.

Schön, D. A. (1987). Educating the reflective practitioner: Toward a new design for teaching and learning in the professions. Jossey-Bass.

Sheridan, K., Halverson, E. R., Litts, B., Brahms, L., Jacobs-Priebe, L., \& Owens, T. (2014). Learning in the making: A comparative case study of three makerspaces. Harvard Educational Review, 84(4), 505-531.

Simon, H. A. (1969). The sciences of the artificial. The MIT Press.

Simon, H. A. (1976). From substantive to procedural rationality. In T. J. Kastelein, S. K. Kuipers, W. A. Nijenhuis, \& G. R. Wagenaar (Eds.), 25 years of economic theory. Springer. https://doi.org/10.1007/978-1-46134367-7_6

Verbeek, P-P. (2016). Toward a theory of technological mediation: A program for postphenomenological research. In J. K. B. O. Friis \& R. P. Crease (Eds.), Technoscience and postphenomenology: The Manhattan papers (pp. 189 -204). Lexington Books.

Wildman, W. J. (2010). An introduction to relational ontology. In J. Polkinghorne (Ed.), The trinity and an entangled world: Relationality in physical science and theology (pp. 55-73). William B. Eerdmans Publishing Company. 